\title{
University Medical Information Network
}

National Cancer Institute

\section{Source}

National Cancer Institute. University Medical Information Network. NCI Thesaurus. Code C132784.

A cooperative organization for national medical schools in Japan designed to: provide upto-date information to healthcare professionals; promote communications between healthcare professionals; support collaborative work among university hospitals; support collaborative medical research; standardize medical data and collect hospital statistics; support education and training at hospitals. 